\title{
Mielorradiculopatia esquistossomótica associada a infecção pelo vírus HBV: relato de caso
}

\author{
Schistosomal myeloradiculopathy associated with hepatitis B \\ virus infection: a case report
}

\begin{abstract}
Rodrigo Tavares Brisson', Fernanda Silva Gonçalves Rodrigues ${ }^{1}$, José Antônio Rebouças de Carvalho Neto, Alex Silva Eduardo ${ }^{2}$, Filippe da Cruz Machado Teixeira ${ }^{2}$, Renata Cristina Franzon Bonatti ${ }^{3}$, Alfredo Leboreiro Fernandez ${ }^{3}$, Cristina da Cunha Hueb Barata de Oliveira ${ }^{4}$
\end{abstract}

Brisson RT, Rodrigues FSG, Carvalho Neto JAR, Eduardo AS, Teixeira FCM, Bonatti RCF, Fernandez AL, Oliveira CCHB. Mielorra-diculopatia esquistossomótica associada a infecção pelo vírus HBV: relato de caso / Schistosomal myeloradiculopathy associated with hepatitis B virus infection: a case report. Rev Med (São Paulo). 2014 out.-dez.;93(4):172-8.

RESUMO: A esquistossomose afeta mais de 200 milhões de pessoas em todo mundo. O envolvimento do Sistema Nervoso Central é raro, porém quando ocorre o acometimento medular é a forma mais frequente e grave. O caso relatado é de um paciente de 19 anos, com quadro de paraparesia assimétrica de evolução progressiva, arreflexia em membros inferiores, incontinência urinária e dor lombar. Havia história prévia de banhos em lagoas de região endêmica para S. mansoni. O líquor apresentava-se com pleocitose de 53 células por $\mathrm{mm} 3$ sendo $3 \%$ de eosinófilos, $87 \%$ de linfócitos, $10 \%$ de monócitos, glicose de $67 \mathrm{mg} / \mathrm{dL}$ e proteínas $176 \mathrm{mg} / \mathrm{dL}$. A ressonância magnética de coluna mostrou lesão extensa de T1 a L2 nas aquisições ponderadas em T2 e impregnação heterogênea pelo contraste em medula lom-bossacra, sugerindo inflamação ativa nesta última região. Apresentou ainda exame parasitológico de fezes positivo para S. mansoni e sorologia positiva para o vírus da hepatite B (VHB) em sua forma crônica. Enfatiza-se neste trabalho que a mielorradiulopatia esquistos-somótica tem critérios diagnósticos clínicos consistentes e o diagnóstico e tratamento precoce é de suma importância para se evitar se-quelas neurológicas e incapacitantes.

DESCRITORES: Neuroesquistossomose/diagnóstico;Vírus da hepatite B; Neuroesquistossomose/terapia; Esquistossomose; Radiculopatia/parasitologia; Hepatite B; Imagem por ressonância magnética; Neuroimagem/métodos; Relatos de casos.

\begin{abstract}
Schistosomiasis affects over 200 million people worldwide. The involvement of the central nervous system (CNS) is rare but when it occurs, the spinal cord damage is the most common and severe form. The reported case is a 19 -years-old patient with asymmetric progressive paraparesis, areflexia in the lower limbs, urinary incontinence and back pain. He used to swim in ponds of endemic area for S. mansoni. Cerebrospinal fluid presented pleocytosis with 53 cells per mm3 where 3\% eosinophils, $87 \%$ lympho-cytes, $10 \%$ monocytes, Glucose $67 \mathrm{mg} / \mathrm{dL}$ protein and $176 \mathrm{mg} / \mathrm{dL}$. Spinal MRI showed extensive damage from T1 to L2 in T2-weighted acquisition and heterogeneous contrast uptake in lumbosacral cord, suggesting active inflammation in the latter region. It also presented positive stools for Schistosoma mansoni and positive serology for hepatitis B virus (HBV) in its chronic form. It's emphasized in this paper that the myeloradiculopathy by schistosomiasis (MRE) has consistent clinical diagnostic criteria and early diagnosis and treatment is of paramount importance to avoid neurological and disabling sequelae.
\end{abstract}

KEYWORDS: Neurochistosomiasis/diagnosis; Hepatitis B virus; Neurochistosomiasis/therapy; Schistosomiasis; Radiculopathy/ parasitology; Hepatitis B; Neroimaging/methods; Magnetic Resonance Imaging; Case reports.

1. Médico Residente de Neurologia do Departamento de Neurologia, Hospital de Clínicas da Universidade Federal do Triângulo Mineiro, Uberaba, MG.

2. Médico Neurologista do Departamento de Neurologia, Hospital de Clínicas da Universidade Federal do Triângulo Mineiro, Uberaba, MG.

3. Médico Neurologista, Professor, Mestre e Doutor em Neurologia do Departamento de Neurologia, Hospital de Clínicas da Universidade Federal do Triângulo Mineiro, Uberaba, MG.

4. Médico Infectologista, Mestre e Doutor do Departamento de Infectologia, Hospital de Clínicas da Universidade Federal do Triângulo Mineiro, Uberaba, MG.

Endereço para correspondência: Hospital de Clínicas da Universidade Federal do Triângulo Mineiro. Avenida Getúlio Guaritá, s/n. Bairro: Abadia. Uberaba, MG, Brasil. CEP:38025-440. E-mail: neurologia@uftm.edu.br. 


\section{INTRODUÇÃO}

A esquistossomose afeta mais de 200 milhões de pessoas em todo mundo. Depois da malária, tem sido descrita como a doença tropical mais comum ${ }^{1}$. O envolvimento do Sistema Nervoso Central (SNC) é raro, sendo o acometimen-to medular a forma mais frequente e grave ${ }^{2,3}$. É uma doença tropical ainda negligenciada e sua prevalência poderia ser drasticamente reduzida com medidas de saúde pública mais eficazes ${ }^{4}$. A mielorradiculopatia esquistossomótica (MRE) tem seu diagnóstico subestimado pelas dificuldades de obtenção de sua confirmação e pela exclusão de seus diagnós-ticos diferencias ${ }^{3}$. O sexo masculino é o gênero mais acometido pela MRE correspondendo de $69-83 \%$ dos casos com idades preferenciais entre 1 e 68 anos de idade (média de 26 anos $)^{5}$, ou seja, indivíduos jovens e produtivos.

A principal determinante da lesão no SNC pela infecção pelo Schistosoma mansoni é a reação inflamatória da deposição de ovos do parasito no tecido nervoso, no caso em questão, no parênquima medular. Isso corre através do fluxo retrógrado existente no plexo de Batson (plexo venoso vertebral interno), avalvular, que contem anastomoses entre o sistema venoso portal/veia cava e as veias do canal espinhal. É por esse fluxo retrógrado, que os ovos do parasi-ta têm acesso ao parênquima medular. Este fator anatômico, associado a características de tamanho e peso dos ovos explica, de maneira clássica, a maior incidência de acometimento medular baixo (medula lombossacra $)^{5,6}$. Há um pro-cesso de necrose lítica e de coagulação logo ao redor do ovo do parasita. Ao redor deste processo há um envelope de macrófagos e células gigantes e mais externamente infiltrado inflamatório rico em eosinófilos e linfócitos. À medida que o processo evolui, pode ocorrer piora progressiva da reação inflamatória ou reação de fibroblastos, formando fibro-se e encapsulamento do ovo, culminando com o término da reação inflamatória ${ }^{5,7,8}$.

Na Fase aguda e hepatoesplênica da esquistosomose, fases em que pode ocorrer a infestação do parasita na medula espinhal, há predomínio de resposta imunológica dependente de Th2 (há a secreção de IL-4 e IL-5 estimulando respectivamente a produção de $\operatorname{IgE}$ pelos linfócitos e proliferação de eosinófilos). A resposta Th2 inibe, por sua vez, a resposta Th1. A Inibição da resposta Th1 pode provocar imunodeficiência relativa e facilitar a multiplicação de vírus e permitir a cronificação destes, como por exemplo o Vírus da Hepatite B (VHB) $)^{9-12}$.

Com maior frequência, o quatro clínico instalase com a tríade prodrômica caracterizada por dor lombar (97,5\% dos casos), alterações de sensibilidade dos membros inferiores (97,5\% dos casos) e disfunção urinária (96,2\% dos ca-sos). Com a evolução da doença, seguem-se fraqueza de membros inferiores e impotência sexual $^{4,13,14}$. O quadro neuro-lógico em geral se instala em
15 dias. Ocasionalmente essa evolução sintomática pode ser lenta e se instalar ao longo de meses. A melhora clínica pode ser espontânea, após o tratamento e em alguns casos pode não ocorrer.

Dentre os achados frequentes no líquor (LCR) na mielorradiculopatia podemos encontrar alterações inespecífi-cas como discreto aumento protéico, níveis normais de glicose, pleocitose com predomínio de linfomononucleares e presença de eosinófilos. Anticorpos anti-Schistossoma por técnica de ELISA foram identificados em $85-90 \%$ dos casos de MRE. É descrito em relatos de casos a presença de bandas oligoclonais ${ }^{4,15}$. $\mathrm{Na}$ ressonância magnética (RM) são fre-quentes os achados de aumento do diâmetro da medula espinhal e/ou das raízes da cauda equina em $\mathrm{T} 1$, hiperintensi-dade do sinal em T2 na região acometida e captação heterogênea do contraste mostrando padrão granular em T1 pós contraste $^{4}$.

O diagnóstico diferencial da MRE deve incluir trauma medular, injeção intratecal, radiação, tumores, deficiên-cia de vitamina B12 ou excesso de folato, síndrome antifosfolípide, vasculite diabética ou autoimune, mielite por HIV, HTLV ou HSV, sífilis, abscessos medulares, tuberculose, mielopatia associada ao vírus $B$ da hepatite, siringomielia e neurocisticercose ${ }^{5}$.

Apresentamos neste artigo, um relato de caso de paciente jovem com mielorradiculopatia esqistossomótica associada à infecção pelo vírus da hepatite B. Além de enfatizar os critérios diagnósticos e a rapidez na instituição do trata-mento para diminuir a probabilidade de sequelas neurológias e incapacidades, lançamos uma reflexão sobre possíveis interações entre a infecção medular pelo $\mathrm{S}$. mansoni e o vírus da hepatite $\mathrm{B}$ e o diferencial de acometimento medular entre elas e contestar o mito de que a esquistossomose é classicamente uma doença que acomete apenas as regiões inferiores da medula torácica e lombar.

\section{RELATO}

Paciente de 19 anos, sexo masculino, solteiro, natural e procedente de Conceição das Alagoas-MG veio para o Hospital de Clínicas da Universidade Federal do Triângulo Mineiro (HC-UFTM) com queixa de "fraqueza nas pernas". Refere que há um mês da internação apresentou fortes dores abdominais, tipo cólica, sem alteração do hábito intestinal, além de dor lombar inespecífica e localizada. Na época, procurou facultativo, foi feito escopolamina venosa com me-lhora parcial da dor. Dois dias após ter cessado a dor, evoluiu com sensação de formigamento nas pernas que ascendeu até os joelhos. Evoluiu nos dias seguintes com fraqueza progressiva das pernas. Passou a deambular com apoio até restrição no leito. Referiu incontinência urinária intermitente. Negou febre ou outros sintomas constitucionais. Após cerca de 
20 dias do início dos sintomas de paraparesia, procurou novamente facultativo de onde veio encaminhado para nosso serviço com hipótese diagnóstica de "Síndrome de Guillain-Barré" (SGB).

No interrogatório sobre a história patológica pregressa e hábitos de vida, referiu banhos em lagoa da região, po-pularmente chamada de "Lagoa Azul" na cidade de Conceição das Alagoas-MG. Referiu ainda gonorreia não tratada há 2 anos. Negou comorbidades.

Ao exame físico clínico\neurológico da admissão encontrava-se em regular estado geral, hipocorado $(2+/ 4+)$, hidratado, acianótico, anictérico, eupnéico em ar ambiente. Lúcido e orientado no tempo, no espaço e circunstancial-mente além de cooperativo ao exame. Apresentava-se em decúbito dorsal passivo, assumindo os diversos decúbitos com dificuldade. De forma sistemática:

- Exame da marcha, equilíbrio e coordenação (em membros inferiores) prejudicados pela paraparesia. Coorde-nação preservada em membros superiores;

- Força grau 1 proximal e distal em membro inferior direito e grau 2 proximal e distal em membro inferior es-querdo;

- Hipotonia em membros inferiores; Tônus preservado em membros superiores;

- Reflexos superficiais: cutâneo plantar indiferente bilateralmente, Hoffman ausente bilateralmente;

- Reflexos profundos: preservados em membros superiores, reflexo patelar e reflexo Aquileu abolidos bilate-ralmente em membros inferiores;

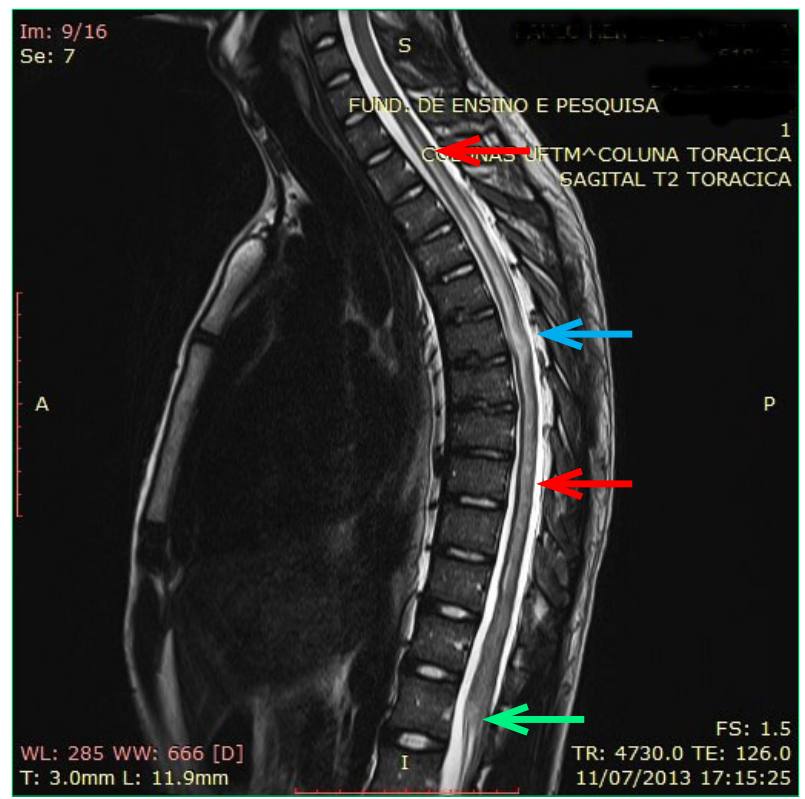

Figura 1- Corte Sagital de RM de coluna torácica ponderada em T2 revelou lesão fusiforme hiperintensa, predominantemente central, com extensão craniocaudal dos níveis T1 a T11(setas vermelhas). Promove expansão medular a nível de T6 (seta azul). Observou-se lesão semelhante no plano de L1-L2 (seta verde). Lesões compatíveis com inflamação/desmielinizaçao da medula tóraco-lombar
- Sem movimentos involuntários;

- Sensibilidade subjetiva com dor em queimação em pernas bilateralmente e objetivamente com sensibilidade preservada para tato, dor e vibração. Não foi observado nível sensitivo;

- Não foram encontradas alterações em nervos cranianos;

- Não foram notados sinais de disautonomia;

- Não havia rigidez nucal;

- Fala e linguagem preservadas;

- Esfíncter vesical incontinente.

Com base na história clínica e no exame neurológico temos:

1. Diagnóstico sindrômico: síndrome mielorradicular caracterizada por disfunção esfincteriana associada a dé-ficit motor;

2. Diagnóstico topográfico: lesão em medula lombar/ sacral e radicular;

3. Diagnóstico etiológico: infecciosa como a mais provável - em decorrência do forte fator de exposição ambi-ental. As causas desmielinizantes e tumorais devem ser descartadas.

A imagens de RM de coluna torácica e lombar ponderadas em T2 revelou lesão fusiforme hiperintensa, predo-minantemente central, com extensão craniocaudal dos níveis T1 a L2. A lesão promove expansão medular a nível de T6. Houve realce heterogêneo pelo contraste em medula torácica baixa e lombar. Lesões compatíveis com inflama-ção/desmielinizaçao da medula tóraco-lombar (Figuras 1 e 2).

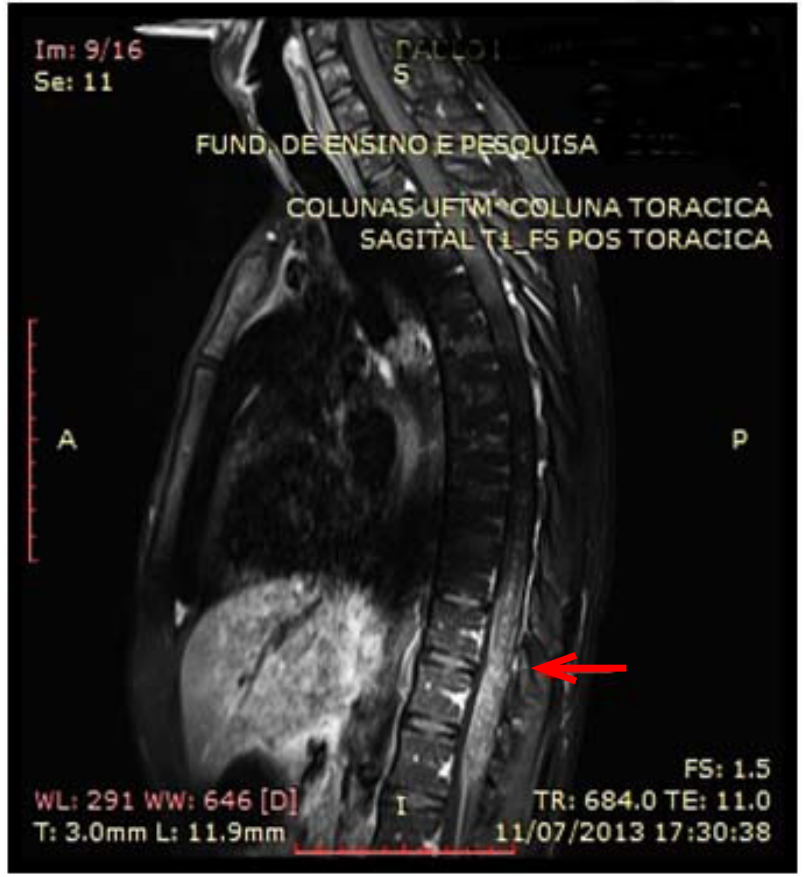

Figura 2- RM de coluna torácica e lombar ponderada em $\mathrm{T} 1$ (pós-contraste) mostrando realce heterogêneo pelo contraste (seta) sugerindo lesão ativa nestas regiões 
O exame do LCR apresentou líquor límpido, incolor, com 1 hemácia por $\mathrm{mm}^{3}, 53$ células por $\mathrm{mm}^{3}$ sendo $3 \%$ de eosinófilos, $87 \%$ de linfócitos, $10 \%$ de monócitos, glicose de $67 \mathrm{mg} / \mathrm{dL}$, proteínas $176 \mathrm{mg} / \mathrm{dL}$, pesquisa para CMV, HVS (1 e 2), HTLV (1 e 2) e cistecercose foram negativas. Bacterioscopia, VDRL, criptolátex, tinta da china e culturas foram também negativos. A imunofluorescência para esquistossomose no LCR foi negativa. A eletroforese de proteínas mostrou presença de bandas oligoclonais.

O hemograma apresentava-se com eosinofilia (6\%) sem leucocitose, proteína $\mathrm{C}$ reativa $(\mathrm{PCR})$ de $0,4 \mathrm{mg} / \mathrm{L}$, enzi-mas hepáticas aumentadas com TGO de 67 U/1 e TGP de 193 U/1. Função renal, função tireoideana, Vitamina B12 e ácido fólico dentro dos limites da normalidade. Pesquisa para hepatite $\mathrm{C}$ negativa. Pesquisa para toxoplasmose, CMV, HTLV 1 e 2, HIV, e VDRL negativas. Sorologia para hepatite B reagente com $\mathrm{HBsAg}+$, Anti-HBc total+, Anti-HBcIgG +, Anti HBcIgM-, HBeAg - e Anti HBe. O HBV-DNA foi de 97 cópias/ml. Exame parasitológico de fezes (EPF) foi positivo, nas três amostras coletadas em dias alternados, para Schistosoma mansoni pela técnica Kato-Katz. Ultrassom abdo-minal total dentro dos limites da normalidade. Urina 1 sem evidencia de infecções.

Feito o diagnóstico de MRE e de hepatite $\mathrm{B}$ crônica. Iniciado tratamento pré-emptivo para VHB com Lamivudina $150 \mathrm{mg} /$ dia antes do início da pulsoterapia com metilprednisona $1 \mathrm{~g}$ /dia por 5 dias seguida de utilização de predni-sona oral com retirada lenta por 6 meses; iniciado praziquantel $50 \mathrm{mg} / \mathrm{kg}$ por 5 dias e notificado o núcleo de vigilância epidemiológica. Paciente recebeu alta para domicílio após 2 semanas de internação.

Cerca de 2 meses após a alta, paciente evoluiu com dor neuropática em membros inferiores. Foi iniciado trata-mento com carbamazepina 200mg 12/12hs com bom controle da dor. Evoluiu nos meses seguintes com melhora pro-gressiva do déficit motor, e na última avaliação após 6 meses de tratamento apresentava força grau 4 proximal e distal em membros inferiores com deambulação sem auxílio e continência de esfíncter vesical. As amostras do EPF de contro-le ( 8 meses após tratamento) mostraram-se negativas para pesquisa Schistosoma mansoni. Paciente encontra-se em acompanhamento no ambulatório de neurologia e de Hepatites Virais do HC-UFTM com controle adequado da infec-ção pelo HBV.

\section{DISCUSSÃO}

O caso relatado representa genericamente um caso de paralisia flácida aguda atribuída a uma síndrome mielorradicular causada pela infecção do parênquima medular por S. mansoni, que representa outra causa comum, vindo de-pois da SGB em menores de $15 \operatorname{anos}^{16}$. Diferentemente da SGB, o acometimento assimétrico de força, de controle esfincteriano precoce, bem como a história clínica e epidemiológica nos direcionam mais para a investigação de outra etio-logia para o acometimento mielorradicular, como a MRE.

O diagnóstico topográfico da lesão, definida pelo exame neurológico, localiza-se com maior frequência na regi-ão torácica baixa ou lombar da medula espinhal, na cauda equina ou no cone medular. Há relatos de acometimento de coluna cervical e cerebelo $0^{4,17,18}$. Paraplegia com flacidez e arreflexia, retenção urinária e redução da sensibilidade tátil, térmica e dolorosa do tipo radicular domina o quadro clínico quando o cone medular e a cauda equina encontram-se acometidos. Já espasticidade, alteração de sensibilidade com nível sensitivo e incontinência urinária predomina no envolvimento medular mais alto. A paraparesia e arreflexia profunda bilateral em membros inferiores são os achados ao exame neurológico mais frequente na mielorradiculopatia. Importante notar que a assimetria de sensibilidade e de motricidade, consequente de alterações nas raízes nervosas, nos sugere MRE dentre as possibilidades diagnósticas ${ }^{4}$.

O diagnóstico de MRE baseou-se nos critérios preconizados pelo Ministério da Saúde do Brasil no Guia de Vi-gilância Epidemiológica e Controle da MRE de 2006:

- Evidência clínica de lesão neurológica medular, mais frequentemente torácica baixa, lombar, cone medular ou cauda equina;

- Demonstração de exposição à esquistossomose por técnicas microscópicas ou sorológicas, tais como por exame parasitológico de fezes (EPF) ou por biópsia retal ou, ainda, por pesquisa de anticorpos circulantes;

- Constatação de LCR anormal, com pleocitose linfomononuclear, elevação de proteínas e positividade de re-ação imunológica específica para esquistossomose (ELISA, imunofluorescência indireta, hemaglutinação); - Exclusão rigorosa de outras causas de mielite transversa.

No caso relatado, observa-se co-infecção pelo HBV em sua forma crônica, o que coloca em evidência a necessidade de se excluir a possibilidade de mielite pelo HBV, ou mesmo, interações entre as duas infecções no hospedeiro. Não encontramos relatos na literatura de associação da mielorradiculopatia esquistossomótica (MRE) associada à in-fecção pelo vírus $\mathrm{B}$ da hepatite (HBV) até o momento nas bases SciELO (Scientific Eletronic Library Online) e Pubmed (U. S. National Library of Medicine). Há apenas artigos com ideias conflitantes em relação a interações na co-infeção Schistosoma mansoni forma intestinal e hepática do HBV sem mencionar a MRE.

A hepatite $\mathrm{B}$ crônica é definida como a permanência do vírus HBV por mais de 6 meses (demonstrada pelo HBsAg+ no soro ou presença de DNA-HBV) com evidência de processo inflamatório do tecido hepático. A maioria dos pacientes evolui oligo ou assintomático com flutuações das transaminases13. A resposta imunológica envolvida na infecção pelo HBV é predominantemente 
Th1, com a estimulação de produção de IL-2 e gamainterferon que promove a citotoxicidade celular protegendo o hospedeiro da replicação viral, importante na fase aguda. Sem esta resposta Th1, há a tendência da cronificação da doença. Como citado anteriormente, a resposta Th1 está diminuída na infecção pelo $\mathrm{S}$. mansoni ${ }^{9,10,12}$. Assim essa imunodepressão relativa da resposta Th1 poderia estar relacionada a cronificação da VHB no hospedeiro coinfectado.

A relação entre HBV e desordens neurológicas são pouco conhecidas 19. Nos poucos casos mencionados na lite-ratura de mielopatia por VHB, foi descrito acometimento medular alto (toraco-cervical) com nível sensitivo e lesões extensas acometendo mais de 3 segmentos medulares. Sintomas extra-hepáticos do VHB como poliarterite nodosa e glomerulonefrite, muitas vezes estão associados ao quadro de acometimento medular ${ }^{20}$.

No LCR da mielopatia por HBV, encontra-se casos na literatura referindo $\mathrm{HBsAg}+$, Anti-HBcIgM - e DNA-HBV positivo. Há associação com níveis séricos elevados de HBsAg em cerca de $3 \%$ dos indivíduos com a forma hepática da shistossomose. Não foi descrito na literatura consultada a presença de bandas oligoclonais e de eosinófilos na mielopa-tia por HBV. Já o LCR na MRE observa-se alterações inespecíficas como discreto aumento protéico, níveis normais de glicose, pleocitose com predomínio de linfomononucleares e presença de eosinófilos, apesar deste último ter pouco potencial diagnóstico para MRE, visto na maioria dos estudos. Anticorpo anti-Schistossoma por técnica de ELISA foram identificados em $85-90 \%$ dos casos de MRE, no entanto, a reação negativa não exclui a possibilidade de infecção pelo parasita, como visto neste caso. É descrito em relatos de casos a presença de bandas oligoclonais, porém sem relevância comprovada na $\mathrm{MRE}^{4,19,21-25}$.

Além da demonstração de exposição à esquistossomose, que no caso em análise se deu pela epidemiologia e EPF, alterações na neuroimagem também são importantes para confirmação do diagnóstico topográfico da MRE. A RM mostra alteração em praticamente todos os casos de MRE, descritas como: aumento do diâmetro da medula espinhal e/ou das raízes da cauda equina em T1. Hiperintensidade do sinal em T2 na região acometida e captação heterogênea do contraste mostrando padrão granular em $\mathrm{T} 1$ pós contraste ${ }^{26,27}$. No caso relatado, observamos lesão medular extensa acometendo praticamente todo o eixo medular. Lesões extensas são tidas como atípicas para a infecção por $\mathrm{S}$. mansoni, contudo, em estudo realizado por Vidal et al. ${ }^{28}$ mostraram em sua casuística que cerca de $50 \%$ dos casos de mielite por S. mansoni foram caracterizados como acometimento extenso da medula em praticamente toda sua extensão. O processo patológico, que poderia justificar a extensão da lesão, seria o envolvimento da deposição à distância de imunocom-plexos decorrentes da reação imunológica ao ovo do parasita e não somente pela reação granulomatosa local ao redor dos ovos28. Com esses dados, somos encorajados a repensar o conceito clássico de que a MRE seja um processo prati-camente restrito a níveis mais baixos da medula espinhal.

Lesões radiológicas semelhantes à da MRE também podem ocorrer na neuromielite óptica (NMO), no HIV, HTLV-1, citomegalovírus (CMV), neurocisticercose, tuberculose e lúpus eritematoso sistêmico (LES). Na NMO as lesões se estendem por mais de três corpos vertebrais, de acentuado hipossinal em T1 e maior associação com atrofia medular. A mielite relacionada ao HIV ocorre em cerca de $5 \%$ a $8 \%$ dos pacientes com síndrome da imunodeficiência adquirida, geralmente associada a um acometimento encefálico severo. No HTLV-1 a mielite está associado a um qua-dro progressivo de paraparesia espástica, sendo o segmento medular mais acometido o torácico podendo estar associa-do a atrofia medular, além de lesões na substância branca encefálica. No CMV, uma polirradiculomielite que envolve frequentemente o cone medular e raízes da cauda equina, a RM apresenta agrupamento e espessamento radicular, com realce pós-contraste, compatível com aracnoidite. Já na neurocistecercose, a RM mostra cistos de conteúdo com sinal semelhante ao líquido cefalorraquiano, com hipossinal em T1 e hipersinal em T2 e o escólex é visto como um nódulo excêntrico próximo à parede do cisto e sua identificação é diagnóstica. Em cistos com algum grau de degeneração pode ser observado realce periférico póscontraste. Na mielite por tuberculose no início do quadro há predomínio de proces-so inflamatório com edema mal definido. Após a formação do granuloma, as lesões se tornam mais definidas, geralmen-te com hipossinal em T1 e iso a hipersinal em T2. Há realce pós-contraste, podendo ser nodular heterogêneo ou anelar periférico, dependendo da presença ou não da necrose caseosa. Por fim, no LES a RM medular demonstra aumento da captação de contraste (edema medular, sinal hiperintenso na ponderação T2 (com menor frequência, sinal iso ou ligei-ramente hipointenso em $\mathrm{T} 1$ ), geralmente atingindo vários segmentos vertebrais e mais frequentemente ao nível da medula toraco-lombar. Assim, estas patologias devem fazer parte do diagnóstico diferencial da MRE ${ }^{29,30}$.

O tatamento da MRE se faz com esquistossomicidas, costicosteróides e/ou cirurgia. Com a destruição do verme adulto, os esquistossomicidas interrompem a produção de ovos e evitam a reação inflamatória no SNC. Os corticoides reduzem a atividade inflamatória em torno dos ovos, e consequente diminuição de compressão e lesão dos nervos. Há melhora significativa após a introdução terapêutica dos corticóide, como foi visto no caso em discussão. A recomenda-ção do manual de vigilância e controle da MRE recomenda a utilização de pulsoterapia com metilprednisolona $1 \mathrm{~g}$ dia IV por 5 dias e continuação de prednisona $1 \mathrm{mg} / \mathrm{Kg}$ de peso em dose 
única pela manhã, por seis meses, com retirada lenta. A cirurgia está reservada para os pacientes com paraplegia aguda e bloqueio liquórico e menos frequente para fins diagnóstico ${ }^{4,14,31}$.

Noventa e cinco por cento dos pacientes com MRE que não recebem tratamento morrem ou não apresentam me-lhora clínica. Cuidados devem ser tomados para se evitar escaras, e o acompanhamento multidisciplinar deve

\section{REFERÊNCIAS}

1. Badr HI, Shaker AA, Mansour MA, Kasem MA, Zaher AA, Salama HH, Safwat MI. Schistosomal myeloradiculopathy due to Schistosoma mansoni: report on 17 cases from an endemic area. Ann Indian Acad Neurol. 2011;14(2):107-10. doi: 10.4103/0972-2327.82796.

2. Algahtani HA, Aldarmahi AA, Al-Rabia MW, Baeesa SS. Acute paraplegia caused by Schistosoma mansoni. Neurosciences (Riyadh). 2014;19(1):47-51.

3. Nascimento GL, Oliveira MR. Severe forms of schistosomiasis mansoni: epidemiologic and economic impact in Brazil, 2010. Trans R Soc Trop Med Hyg. 2014;108(1):2936. doi: $10.1093 / \operatorname{trstmh} / \operatorname{trt} 109$.

4. Brasil. Ministério da Saúde. Secretaria de Vigilância em Saúde. Guia de vigilância epidemiológica e controle da mielorradiculopatia esquistossomótica. Brasília: Ministério da Saúde. 2006. Disponível em: http://bvsms.saude.gov.br/ bvs/publicacoes/07_0061_M.pdf.

5. Silva LCS, Maciel EP, Ribas JGR, Pereira SR, Serufo JC, Andrade LM, Antunes CM, Lambertucci JR. Schistosomal myeloradi-culopathy. Rev Soc Bras Med Trop. 2004;37(3):261-72. http://dx.doi.org/10.1590/S003786822004000300013 .

6. Matas SLA. Neuroesquistossomose. Rev Neurociências. 2001;9(1):27-31. Disponível em: http://goo.gl/D017sG.

7. Budzilovich GN, Most H, Feigin I. Pathogenesis and latency of spinal cord schistosomiasis. Arch Pathol. 1964;77:383-8.

8. Ross AG, McManus DP, Farrar J, Hunstman RJ, Gray DJ, Li YS. Neuroschistosomiasis. J Neurol. 2012;259(1):22-32. doi: 10.1007/s00415-011-6133-7.

9. Serufo JC, Lambertucci JR. Esquistossomose e hepatites virais: uma revisão. Rev Soc Bras Med Trop. 1997;30:313-322. http://dx.doi.org/10.1590/S003786821997000400007 .

10. Nooman ZM, Nafeh H, Elwan SI. Hepatitis B antigen in bilharzial subjects infected with viral hepatitis. In: Proce- incluir fisioterapia, cuidados de enfermagem, psicologia, terapia ocupacional e Neurologia ${ }^{4,29}$. O médico deve notificar a secretaria de saúde municipal ou estadual todo caso confirmado ou mesmo suspeito de MRE. Nos países em que a esquistos-somose ainda apresenta uma alta prevalência, como o Brasil, os pacientes com sintomatologia semelhante ao do caso relatado, devem levar o examinador a pensar nessa hipótese diagnóstica.

edings of the International Congress on Schistosomiasis; 1978. p.149-55.

11. Pearce EJ, Caspar P, Grzych JM, Lewis FA, Sher A. Downregulation of Th1 cytokine production accompanies induction of Th2 responses by a parasitic helminth, Schistosoma mansoni. J Exp Med. 1991;173:159-66. Available from: http://jem.rupress.org/content/173/1/159.long.

12. Williams ME, Montenegro S, Domingues AL, Wynn TA, Teixeira K, Mahanty S, Coutinho A, Sher A. Leukocytes of patients with Schistosoma mansoni respond with a Th2 pattern of cytokine production to mitogen or egg antigens but with a Th0 pattern to worm antigens. J Infect Dis. 1994;170:946-54. doi: 10.1093/infdis/170.4.946.

13. Tavares W, Marinho LAC. Rotinas de diagnóstico e tratamento das doenças infecciosas e parasitárias. $4^{\mathrm{a}}$ ed. Rio de Janeiro: Atheneu; 2005. p.529-35.

14. Peregrino AJP, Puglia PMK, Nóbrega JPS, Livramento JA, Marques-Dias MJ, Scaff M. Esquistossomose medular: análise de 80 casos. Arq Neuropsiquiatr 2002;60(Suppl 1):6038. http://dx.doi.org/10.1590/S0004-282X2002000400016.

15. Livramento JA, Machado LR, Silva CL, Spina França A. Síndrome do líquido cefalorraquiano na neuroesquistossomose. Arq Neuropsiquiatr 1985;43(Suppl 1):372-7. http:// dx.doi.org/10.1590/S0004-282X1985000400006.

16. Dias-Tosta E, Kückelhaus CS. Guillain Barré syndrome in a population less than 15 years old in Brasil. Arq Neuropsiquiatr. 2002;60(2-B):367-73. http://dx.doi.org/10.1590/ S0004-282X2002000300005.

17. Braga BP, Costa Junior LB da, Lambertucci JR. Magnetic resonance imaging of cerebellar schistosomiasis mansoni. Rev Soc Bras Med Trop. 2003;36(5):635-6. http://dx.doi. org/10.1590/S0037-86822003000500018.

18. Silva LCS, Kill CM, Lambertucci JR. Cervical spinal cord schistosomiasis. Rev Soc Bras Med Trop. 2002;35(Suppl 1):543-4. http://dx.doi.org/10.1590/S003786822002000500023 .

19. Inoue J, Ueno Y, Kogure T, Nagasaki F, Kimura O, Obara N, Kido O, Nakagome Y, Kakazu E, Matsuda Y, Fukushima K, Sega-wa H, Nakajima I, Itoyama Y, Takahashi M, Okamoto 
H, Shimosegawa T. Analysis of the full-length genome of hepatitis B virus in the serum and cerebrospinal fluid of a patient with acute hepatitis B and transverse myelitis. J Clin Virol. 2008;41(4):301-4. doi: 10.1016/j.jcv.2008.01.002.

20. Stübgen JP. Immune-mediated myelitis associated with hepatitis virus infections. J Neuroimmunol. 2011;239(12):21-7. doi: 10.1016/j.jneuroim.2011.09.001.

21. Onder B, Ozer NB, Onder FO, Selcuk B, Kurtaran A, Yalcin $\mathrm{E}$, Akyüz M. Incidence of acute hepatitis B in patients with spinal cord injury. Spinal Cord. 2011;49(12):1155-7. doi: $10.1038 /$ sc.2011.80.

22. Santos-García D, Arias-Rivas S, Dapena D, Arias M. Past hepatitis B virus infection and demyelinating multiphasic disease: casual or causal relationship? Neurologia. 2007;22(8):542-6.

23. Matsui M, Kakigi R, Watanabe S, Kuroda Y. Recurrent demyelinating transverse myelitis in a high titer HBs-antigen carrier. J Neurol Sci. 1996;139(2):235-7.

24. Aquino RTR, Chieffi PP, Catunda SM, Araujo MF, Ribeiro MCSA, Taddeo EF, Rolim EG. Hepatitis B and C virus markers among patients with hepatosplenic mansonic schistosomiasis. Rev Inst Med Trop Sao Paulo 2000;42(6):313-20. http://dx.doi.org/10.1590/S0036-46652000000600003.

25. Lambertucci JR, Serufo JC, Gerspacher-Lara R, Rayes AA, Teixeira R, Nobre V, Antunes CM. Schistosoma mansoni: assessment of morbidity before and after control. Acta Trop. 2000;77(Suppl 1):101-9. doi:10.1016/S0001-706X(00)00124-8.
26. Lambertucci JR, Pereira SRS, Silva LC. Myeloradiculopathy in acute schistosomiasis mansoni. Rev Soc Bras Med Trop. 2005;38(3):277-8. http://dx.doi.org/10.1590/S003786822005000300019 .

27. Peregrino AJP, Oliveira SP, Porto CA, Santos LA, Menezes EE, Silva AP, Brito AL, Pinheiro SP, Pinheiro S, Dias AB. Menin-gomielorradiculite por Schistosoma mansoni: Protocolo de investigação e registro de 21 casos. Arq Neuropsiquiatr 1988; 46:49-60. Disponível em: http://www.scielo. br/pdf/anp/v46n1/09.pdf.

28. Vidal CHF, Ferreira MLB, Azevedo Filho HRDC, Gurgel FV, Brainer-Lima AM. Extensive spinal cord involvment in magnetic resonance imaging evaluation on schistosomal myelitis. Arq Neuropsiqtr. 2012;70(3):210-3. http://dx.doi. org/10.1590/S0004-282X2012000300011.

29. Carvalho GBS, Sandim GB, Tibana LAT, Tertuliano FF, Igagawa MH, Abdala N.. Diagnóstico diferencial das lesões inflamatórias e infecciosas do cone medular utilizando a ressonância magnética. Radiol Bras. 2013;46(1):51-5. http://dx.doi.org/10.1590/S0100-39842013000100014.

30. Sampaio MJ, Garrido A, Oliveira MJ. Mielite transversa aguda. Nascer Crescer. 2011;20(1):32-4. Disponível em: http://www.scielo.oces.mctes.pt/pdf/nas/v20n1/v20n1a07. pdf.

31. Silva LCS, Maciel PE, Ribas JG, Souza-Pereira SR, Antunes CM, Lambertucci JR. Treatment of schistosomal myeloradiculopa-thy with praziquantel and corticosteroids and evaluation by magnetic resonance imaging: a longitudinal study. Clin Infect Dis. 2004;39(11):1618-24. doi: 10.1086/425611. 